\title{
Streamflow and its components in Ebinur basin: decoupling of anthropogenic and climatic elements
}

\author{
bao qingling ${ }^{1}$, ding jianli ${ }^{1}$, liu $\mathrm{jie}^{1}$, han lijie $^{1}$, and wang yinghui ${ }^{1}$ \\ ${ }^{1}$ Xinjiang University
}

May 7, 2021

\begin{abstract}
Detecting and assessing changes in the hydrological cycle and how it responds to a changing environment is essential for maintaining regional ecological security and restoring damaged ecosystems. The Ebinur Lake basin, an important ecological barrier in the Junggar Basin of Xinjiang, China, has undergone significant changes in recent decades as a result of massive ecorehabilitation projects and increased anthropogenic factors. Former studies concentrated on the effect of environmental changes on total runoff, while studies on runoff components in arid region were absent. To solve the above defects, we separated the study period into three phases based on the heuristic segmentation algorithm:the reference phase (1964-1985) and two impact phases: I (1986-2000) and II (2001-2017). The Variable Infiltration Capacity (VIC) surface models were used to determine the contribution of both human activities and climate change to streamflow along with its components. Based on the VIC model of streamflow splitting, the results showed that surface runoff, baseflow and snowmelt accounted for $20.97 \%, 60.37 \%$ and $23.42 \%$ of the annual runoff volume respectively. The differential evolution Markov chain (DEMC) algorithm improved the Nash-Sutcliffe efficiency by $20 \%$ over the traditional SCE-UA algorithm, which exceeded 0.6 and reached reliable level. Increases in cropland and forested land were partially contributed by grassland and heathland throughout the study period, While the leaf area index (LAI) of the season of plant growth showed a trend of 0.002 increase per year. Direct human activity was the main factor in the reduction of runoff in impact phase I and indirect human activity in impact phase II, Whereas, in the total impact phase, climate change was the main driver of runoff increase. Our results provide insight into decision making related to water stress in changing circumstances in arid regions.
\end{abstract}

\section{Hosted file}

HP_bao_7500.pdf available at https://authorea.com/users/412444/articles/521155-streamflowand-its-components-in-ebinur-basin-decoupling-of-anthropogenic-and-climatic-elements

\section{Hosted file}

table.pdf available at https://authorea.com/users/412444/articles/521155-streamflow-and-itscomponents-in-ebinur-basin-decoupling-of-anthropogenic-and-climatic-elements

\section{Hosted file}

fig.pdf available at https://authorea.com/users/412444/articles/521155-streamflow-and-itscomponents-in-ebinur-basin-decoupling-of-anthropogenic-and-climatic-elements 